\title{
Consequences of morphology and tissue strength to blade survivorship of two closely related Rhodophyta species
}

\author{
Frank J. Shaughnessy ${ }^{1, *}$, Robert E. De Wreede ${ }^{2}$, Emily C. Bell $^{3}$ \\ 'Department of Plant Biology, Louisiana State University, Baton Rouge, Louisiana 70803-1705, USA \\ ${ }^{2}$ Department of Botany, University of British Columbia, Vancouver, British Columbia, Canada V6T 1Z4 \\ ${ }^{3}$ Department of Zoology, University of British Columbia, Vancouver, British Columbia, Canada V6T 1 Z4
}

\begin{abstract}
In Barkley Sound, British Columbia, Canada, the wide-bladed red alga Mazzaella splendens occurs intertidally at low to intermediate wave exposure sites but not at adjacent high wave exposure intertidal sites that are occupied by the narrow-bladed sister species Mazzaella linearis. This study used morphological and biomechanical characteristics of both species to determine whether or not drag and acceleration forces could prevent blades of $M$. splendens from surviving at high exposure sites and hence account, in part, for their distributions. For each species, these hydrodynamic forces were calculated for gametophyte and sporophyte phases and, when possible, short and long thalli. The most frequent break location when thalli were pulled by a spring-scale was the junction between the stipe and holdfast. The following predictions were made by a model that compared hydrodynamic forces which a blade would experience to the measured force required to break the stipe/holdfast junction: (1) long blades of $M$. splendens should not occur at high wave exposure sites, (2) within the range of wave exposure occupied by $M$. splendens, sporophytes should be more abundant than gametophytes when and where wave exposure is greatest and (3) long blades of $M$. linearis are predicted to occur at high wave exposure sites. All 3 of these predictions agree with other studies of natural populations. Two predictions do not agree with field observations: (1) long $M$. linearis gametophytes are predicted to have greater survivorship at higher water velocities than long sporophytes but, in natural populations, sporophytes are actually more abundant when wave action is greater and (2) short blades of $M$. splendens are predicted to survive very high water velocities but, in reality, are absent from high wave exposure sites in Barkley Sound. The latter contradiction suggests that recruitment of $M$. splendens at high wave exposure sutes is prevented at a life history stage prior to the development of short blades.
\end{abstract}

KEY WORDS: Mazzaella Iridaea Gametophyte Sporophyte - Drag Acceleration Survivorship

\section{INTRODUCTION}

There is limited understanding of the role that selective forces have in maintaining habitat differences among ecotypes or closely related species of seaweeds. Studies usually consist of correlations between environmental variables and species distributions. For example, locations of Sargassum species among intertidal habitats may be maintained by varying intensities of desiccation (McCourt 1984a, b). Correlations also

\footnotetext{
•E-mail: fshaugh@unix1.sncc.lsu.edu
}

exist between wave exposure and blade width such as for populations of Chondrus crispus (Gutiérrez \& Fernández 1992) and Durvillaea potatorum (Cheshire \& Hallam 1988). In some instances, such as for species of Gracilaria, habitat differences among species are not apparent in which case the scale used to describe habitats may have been too coarse (Hay \& Norris 1984), or random disturbance and dispersal events may be more important than selection in affecting species distributions.

The present study asks why the red seaweed Mazzaella splendens is absent from sites occupied by $M$. linearis (Gigartinaceae, Rhodophyta; formerly as Iri- 
daea cordata, I. lineare). Relative to other species in the Gigartinaceae, $M$. splendens and $M$. linearis are closely related because they have similar carposporangial anatomy (Kim 1976) as well as similar base sequences for the large subunit of the Rubisco gene (Hommersand et al. 1994). The 2 species are distinguished by the depth of the tetrasporangial sorus in the blade (Kim 1976) and, in Barkley Sound, Canada, $M$. splendens has a short thin stipe with wide or intermediate-width blades whereas $M$. linearis has a long thick stipe and narrow blades (Shaughnessy 1996). A reciprocal common garden experiment where each species was regrown from holdfasts demonstrated that these vegetative differences were due to genetic differentiation rather than phenotypic plasticity (Shaughnessy 1994). In Barkley Sound, blades of $M$. splendens occur in low intertidal sites subject to either low or intermediate wave exposure but are not found at adjacent low intertidal, high wave exposure sites where $M$. linearis occurs (Shaughnessy 1996). However, due to their close spatial proximity, spores of one species are probably being dispersed to sites of the other species. Holdfasts of $M$. splendens could be occurring within high wave exposure sites but, without stipes and blades, could be overlooked or not recognizable as $M$. splendens.

Hydrodynamic forces at high wave exposure sites occupied by Mazzaella linearis could account in part for the absence of $M$. splendens blades at these sites. The primary hydrodynamic forces seaweed species encounter are drag and accelerational forces (Denny et al. 1985, Gaylord et al. 1994). Drag is proportional to the square of water velocity and the thallus area projecting in the direction of force (Carrington 1990, Gaylord et al. 1994). The accelerational force is proportional to water acceleration and volume of fluid displaced by the organism (Denny 1987, 1988). Wide blades of $M$. splendens may provide so much surface area that drag forces at high water velocities exceed the force required to break tissue.

The first step in our approach was to measure the breaking force needed to remove a blade of Mazzaella splendens or $M$. linearis from a holdfast. This breaking force is the critical measure which indicates the upper hydrodynamic load a thallus can withstand before tissue failure occurs. Breaking forces could vary due to differences in morphology or strength (i.e. break force/break area). For example, if the first hypothetical species has a greater stipe break force and a thicker stipe than the second species, and stipe tissue strength is similar, then the morphological difference between species is the only reason that break forces differ. In contrast, if the first species has a greater stipe break force but stipe morphology is similar between species, then the first species has greater strength. The latter strength difference could be attributed to the internal arrangement of tissues, cells or structural molecules. The second step in this study was to model drag and accelerational forces which would be experienced by the blade. As modeled hydrodynamic forces approach the break force needed to remove a blade from a holdfast, the probability of blade survival decreases. Survivorship was calculated for gametophytes and sporophytes of each species and for short and long size classes since, for both species and particularly $M$. splendens, gametophytes have wider blades than sporophytes (Shaughnessy 1996) and blade areas must be lower for short versus long thalli.
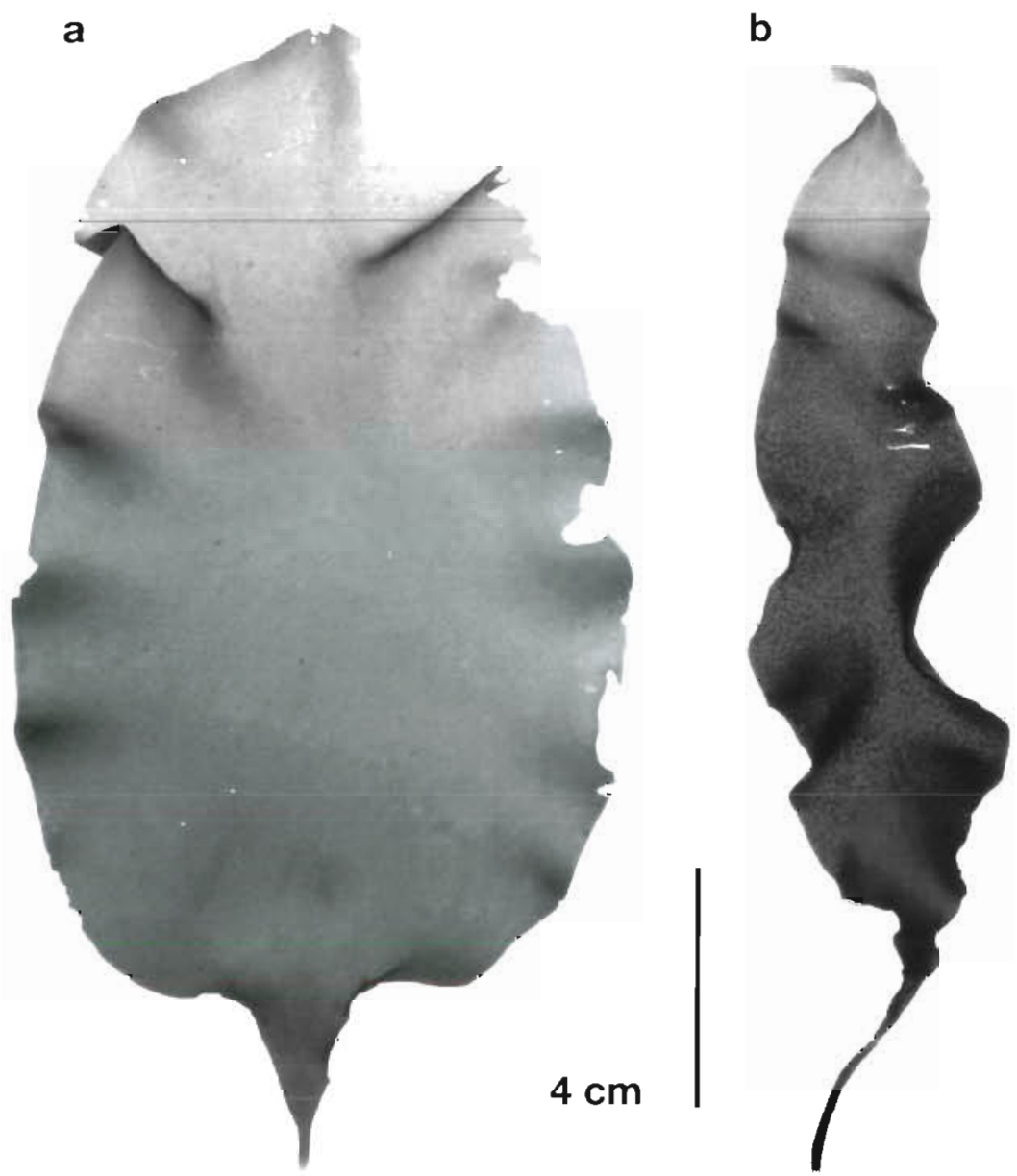

Fig. 1 (a) Long nonreproductive Mazzaella splendens and (b) tetrasporangial $M$. linearis; stipes and blades are shown but not holdfasts 


\section{MATERIALS AND METHODS}

Wave exposure and sampling. Mazzaella splendens (Figs. 1a \& 2a) and M. linearis (Figs. 1b \& 2b) were sampled haphazardly from low intertidal sites within Second Beach and Nudibranch Point, respectively, in Barkley Sound on the west coast of Vancouver Island, British Columbia, Canada $\left(48^{\circ} 50^{\prime} \mathrm{N}, 125^{\circ} 10^{\prime} \mathrm{W}\right.$; Fig. 3). Actual measures of water velocity were not made at the 2 study sites. Several indirect measures of wave exposure were made and these included the substratum slope and maximum elevation of $M$. splendens or $M$. linearis above Lowest Normal Tide (LNT; Canadian Chart Datum). Also measured when the tide was high enough to keep Mazzaella thalli covered was the mean weight lost by sucrose candies (Wild Cherry Lifesavers, Hershey Canada, Inc., Etobicoke, ON, Canada) when submerged adjacent to thalli for $2 \mathrm{~min}$ on 3 dates (12 lifesavers per date; November 3, 1990; December 30, 1990; April 13, 1991). The most abundant sessile invertebrates and perennial macrophytes at the maximum elevation of Mazzaella at each site and at the lowest sampled elevation of each site were also recorded

For each species and within each life cycle phase (i.e. gametophyte, sporophyte), 2 size classes (SC) were selected on June 4, 1993 and June 20, 1994 (SC1. $2.5-6.0 \mathrm{~cm}$ long; SC2: $15.0-30.0 \mathrm{~cm}$ ). Only undamaged and nonsenescing individuals were used. The resorcinol test as modified by Garbary \& De Wreede (1988) was used to identify vegetative thalli as gametophytes a

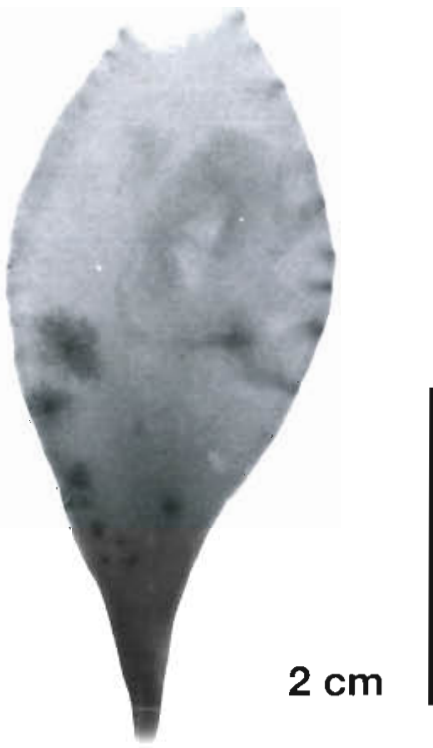

b

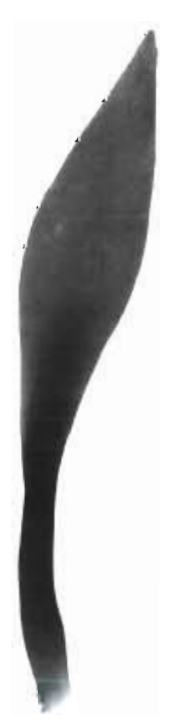

Fig. 2. Short (a) Mazzaella splendens and (b) M. linearns; stipes and blades are shown but not holdfasts

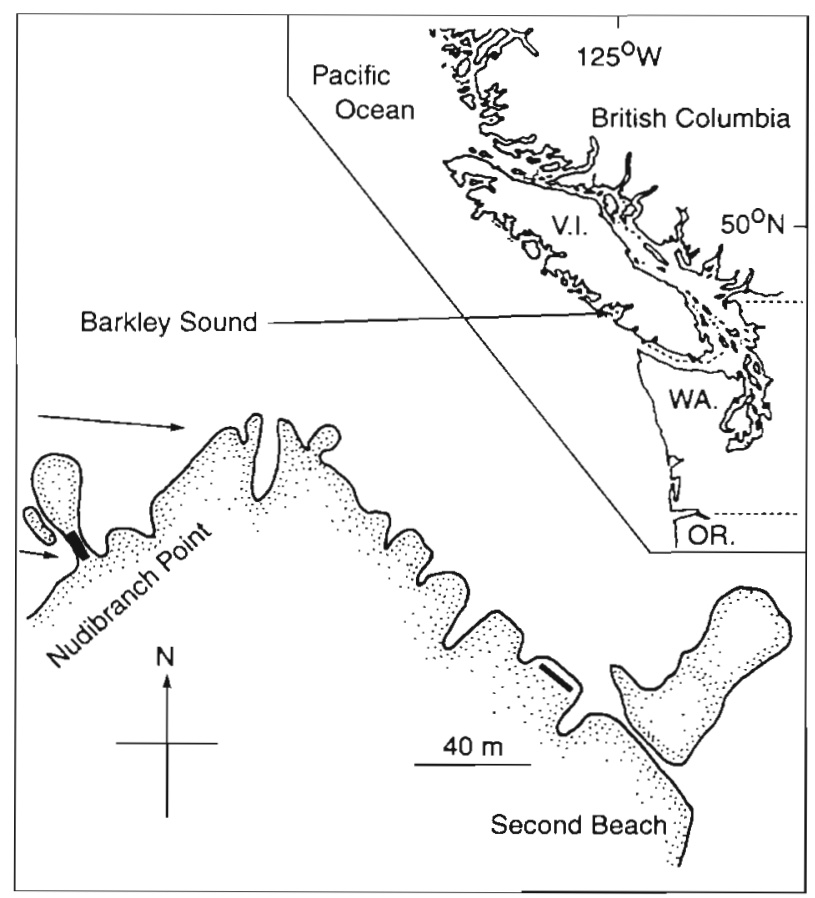

Fig. 3. Location of sites (dark bars) within Nudibranch Point and Second Beach where, respectively, Mazzaella linearis and $M$. splendens were sampled; arrows indicate predominant direction of swell. V.l. = Vancouver Island, British Columbia; WA $=$ Washington; OR. = Oregon

or sporophytes. Breaking force was measured by folding the upper half of each blade over a bent strip of aluminum that had rubber pads glued to each side. A foldback clip (Acme United, Ltd.; sold commercially to hold paper together), with rubber glued to the inside, was used to grab the strip and blade. A metal loop from the paper clamp was hooked to a $5.0 \mathrm{~kg}$ spring-scale which was pulled smoothly and rapidly (about $1.5 \mathrm{~s}$ ) at a $45^{\circ}$ angle to the substratum. A magnet on the springscale moved to the maximum weight at which the thallus broke. A hoffman open side tubing clamp (Fisher Scientific), stronger than the foldback clip but also padded with rubber on the inside, had to be used to detach SC1 Mazzaella linearis because these thalli were so strongly attached. For all thalli, any breaks that occurred within either clamp were discarded since it is possible that in these cases tissue had been damaged by the clamp. The location where each thallus broke was noted: blade, stipe, stipe/holdfast junction (= junction), holdfast, or substratum if the actual rock or shell broke. Kilogram measures from the springscale were converted to breaking force $(\mathrm{N})$ by multiplying by the acceleration of gravity (i.e. $9.81 \mathrm{~m} \mathrm{~s}^{-2}$; Denny 1988).

Area measures and analyses. Planform area $(A)$ is the area projected by the thallus in the plane parallel to flow (Gaylord et al. 1994). This was measured by 
spreading each fresh blade with stipe between 2 sheets of Plexiglas and photocopying. Planform area of each photocopy was measured using the Kontron Image Processing System. For thalli that broke at the junction, vernier calipers were used to immediately measure the break surface in 2 dimensions. Since the 2 dimensions were unequal, junction cross-sectional area was determined using the equation for an ellipse. Junction tissue strength [in meganewtons (MN) $\mathrm{m}^{-2}$ ] was calculated as junction breaking force divided by junction cross-sectional area.

Statistical analyses were performed using SYSTAT (v. 5.03). SC1 and SC2 were separately analyzed since we felt this approach was most easily interpreted. For SC1 Mazzaella splendens, independent sample $t$-tests for equal variances were used to compare planform area, junction break force, junction strength and junction cross-sectional area. For SC2, the same dependent variables were assessed using model I nested analysis of variance (ANOVA). SPECIES ( $M$. splendens and $M$. linearis) were compared with phase (gametophyte and sporophyte) nested within each species: PHASE\{S\}. Assumptions of normality and homogeneity of variances were checked respectively with probability plots and plots of estimates against residuals. If transformations were necessary to meet assumptions, they are indicated in the legend of the ANOVA table. If necessary, $F$ tests (numerator $\mathrm{df}=1$ ) were used to make posthoc comparisons of phases within each species; these were done using the 'specify hypotheses' commands in SYSTAT (Wilkinson 1990).

Probability of removal. A cumulative probability distribution of forces required to break the stipeholdfast junction was constructed for each of the following groups of thalli: SC2 Mazzaella splendens gametophytes, SC2 $M$. splendens sporophytes, SC2 $M$. linearis gametophytes and SC2 $M$. linearis sporophytes. This distribution was also made for SC1 $M$. splendens but phases were not distinguished because they were not significantly different for planform area or junction break force. No distribution was made for SC1 $M$. linearis because not enough thalli could be sampled. Each of the above cumulative probability distributions was created when ranked junction break forces were plotted against the probability of encountering break forces. This probability was calculated by sorting junction break forces from low to high, assigning a rank to each force, and dividing the rank by $n+1$ where $n$ was the number of thalli in the group. A modified Weibull model (Denny \& Gaines 1990) was fit to these nonlinear distributions using SYSTAT commands given in Appendix 1

Hydrodynamic forces. The total hydrodynamic force $\left(F_{1}\right)$ on a thallus is the sum of $\operatorname{drag}\left(F_{0}\right)$ and acceleration $\left(F_{a}\right)$ forces (Gaylord et al. 1994). $F_{t}$ for each velocity was inserted into the Weibull equation describing each group (Appendix 2) yielding the probability of tissue failure at the stipe/holdfast junction. These probabilities were then converted to \% survivorship.

The force $(\mathrm{N})$ on a thallus due to drag is:

$$
F_{\mathrm{d}}=(1 / 2) C_{\mathrm{d}} p A u^{2}
$$

where $C_{d}$ is the coefficient of drag, $p$ is the density of salt water $\left(1025 \mathrm{~kg} \mathrm{~m}^{-3}\right), A$ is planform area $\left(\mathrm{m}^{2}\right)$, and $u$ is water velocity $\left(\mathrm{m} \mathrm{s}^{-1}\right)$ relative to the thallus (Gaylord et al. 1994). Upper and lower 95\% confidence limits for mean $A$ were used in order to show the potential range of survivorship for a particular species, size class and phase. These confidence limits were adjusted for sample size and if a group had a nonnormal distribution for $A$, then confidence limits were calculated on transformed data and converted back to original units according to Gardner \& Altman (1989). A $C_{d}$ for Mazzaella flaccida (i.e. 0.055; Carrington 1990, as Iridaea flaccida) was used in our calculations due to the similarity of $M$. flaccida and $M$. splendens blade morphologies (Foster 1982).

Force $(\mathrm{N})$ on a thallus due to acceleration was calculated using the equation:

$$
F_{\mathrm{a}}=C_{\mathrm{m}} p V \mathrm{a}
$$

where $C_{m}$ is the inertia coefficient of 5.58 (mean of positive $C_{m}$ values for Mazzaella flaccida in Gaylord et al. 1994), $p$ is the density of salt water, $V$ is thallus volume $\left(\mathrm{m}^{3}\right)$, and $a$ is water acceleration $\left(\mathrm{m} \mathrm{s}^{-2}\right)$ relative to the thallus (Gaylord et al. 1994). $V$ was estimated from confidence limits of $A$ using a relationship established for $M$. flaccida ( $V=0.00145 A^{099}$; Gaylord et al. 1994). Acceleration (a) was assumed to be $20 \mathrm{u}$. This is a reasonable approximation based on the few available measurements of water acceleration in the surf zone. This relationship yields an a of approximately $100 \mathrm{~m} \mathrm{~s}^{-2}$ for a wave sheltered site (approx. $u$ of $5 \mathrm{~m} \mathrm{~s}^{-1}$ ) and about $300 \mathrm{~m} \mathrm{~s}^{-2}$ for a wave exposed site which agrees with values cited by Denny et al. (1985) and Gaylord et al. (1994)

\section{RESULTS}

The site at Nudibranch Point where Mazzaella linearis was sampled has a steep shoreline and receives almost full open ocean swell, whereas the site at Second Beach where $M$. splendens was sampled is leeward of this headland and has a less steep shoreline (Fig. 3, Table 1). At Nudibranch Point, sucrose candy weight loss was $3 \times$ greater than at Second Beach and $M$. linearis reached ca $0.60 \mathrm{~m}$ higher in the intertidal than $M$. splendens (Table 1). The lowest elevation sampled for each species was ca $0.0 \mathrm{~m} \mathrm{LNT}$; this eleva- 
Table 1. Comparison of physical and biological wave exposure indicators at each site; upper and lower elevations for taxa correspond to the maximum vertical elevation and the lowest elevation sampled for Mazzaella splendens and $M$. linearis. $\mathrm{n}$ : sample size; SEM: standard error of the mean

\begin{tabular}{|lll|}
\hline Wave exposure indicator & Second Beach & Nudibranch Point \\
\hline $\begin{array}{l}\text { Mean }(n, S E M) \text { upper } \\
\text { elevation }(\mathrm{m} \text { above LNT) }\end{array}$ & Mazzaella splendens: $0.92(6,0.04)$ & Mazzaella linearis: $1.56(6,0.10)$ \\
Mean $(\mathrm{n}, \mathrm{SEM})$ candy weight loss $(\mathrm{g})$ & $0.49(36,0.02)$ & $1.56(34,0.05)$ \\
Mean $(\mathrm{n}, \mathrm{SEM})$ slope $\left({ }^{\circ}\right)$ & $14.3(3,1.2)$ & $55.0(5,4,45)$ \\
Upper elevation macrophytes & Egregia menziesii, Fucus gardneri, & Hedophyllum sessile, \\
& Prionitis lanceolata & Lessoniopsis littoralis \\
Lower elevation macrophytes & Hedophyllum sessile, Chondracanthus & Lessoniopsis littoralis, Laminaria \\
& corymbiferus ${ }^{\mathrm{a}}$, Phyllospadix scouleri & setchellii, Corallina vancouveriensis \\
Upper elevation invertebrates & & Pollicipes polymerus, Semibalanus \\
& & cariosus, Mytilus californianus \\
aFormerly as Gigartina corymbifera & & \\
\hline
\end{tabular}

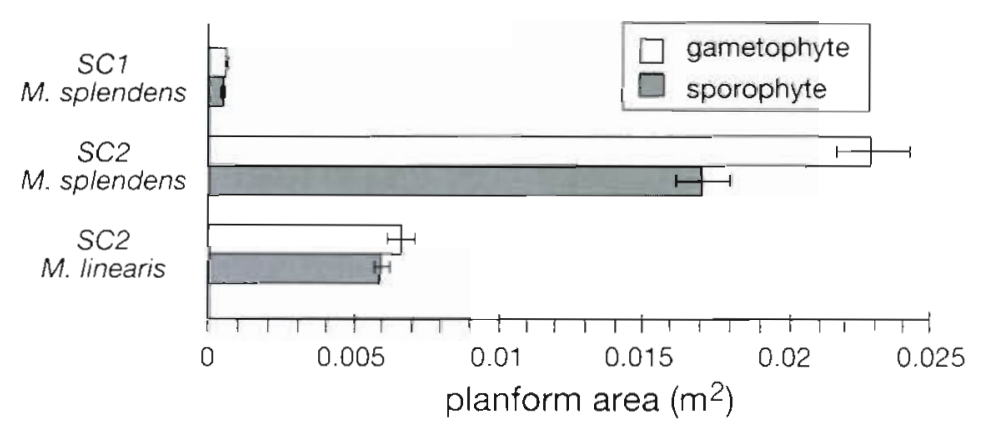

Fig. 4. Mean ( \pm 1 SEM) planform areas for both Mazzaella species and phases

tion was the lower limit for $M$. linearis but $M$. splendens extends ca $3.0 \mathrm{~m}$ into the subtidal at Second Beach (F.J.S. pers. obs.).

Phases of SC1 Mazzaella splendens did not significantly differ in planform area ( $p=0.896$, Fig. 4). For SC2, SPECIES and PHASE\{S\} were each significant and the entire ANOVA model had an $\mathrm{R}^{2}$ of $71 \%$ for planform area variation (Table 2). $M$. splendens always

Table 2. Nested ANOVA table for differences among SC2 means of planform area (natural log transformed); significant differences: $" p<0.01$; F-test comparisons at the table bottom that share an underline were not significantly different $(\mathrm{p}<$ $0.05)$, splen $=$ Mazzaella splendens, lin. $=M$. linearis, gam. $=$ gametophyte, sporo. $=$ sporophyte

\begin{tabular}{|lrrrr|}
\hline Effect & df & \multicolumn{1}{c}{ MS } & $F$ & $p$ \\
\hline SPECIES & 1 & 76.452 & 514.679 & $\cdots$ \\
PHASE $\{S\}$ & 2 & 0.981 & 6.609 &.$\cdot$ \\
Error & 258 & 0.148 & & \\
splen. gam. & splen. sporo., & lin. gam. lin. sporo. & \\
\hline
\end{tabular}

had greater planform areas than $M$. Linearis and, for each species, gametophyte area was greater than sporophyte area, but this difference was only significant for $M$. splendens (Fig. 4, Table 2).

For each group of algae tested, the greatest proportion of thalli broke at the junction between stipe and holdfast. This proportion ranged from 0.59 for SC2 Mazzaella splendens sporophytes to 0.88 for SC2 $M$. linearis sporophytes (Fig. 5). Most instances of holdfast breaks only removed a small piece of holdfast. Substratum breaks occurred when holdfasts were attached to unstable bedrock or barnacles.

The force required to break junctions of SC1 Mazzaella splendens phases (Fig. 6) did not differ ( $\mathrm{p}=$

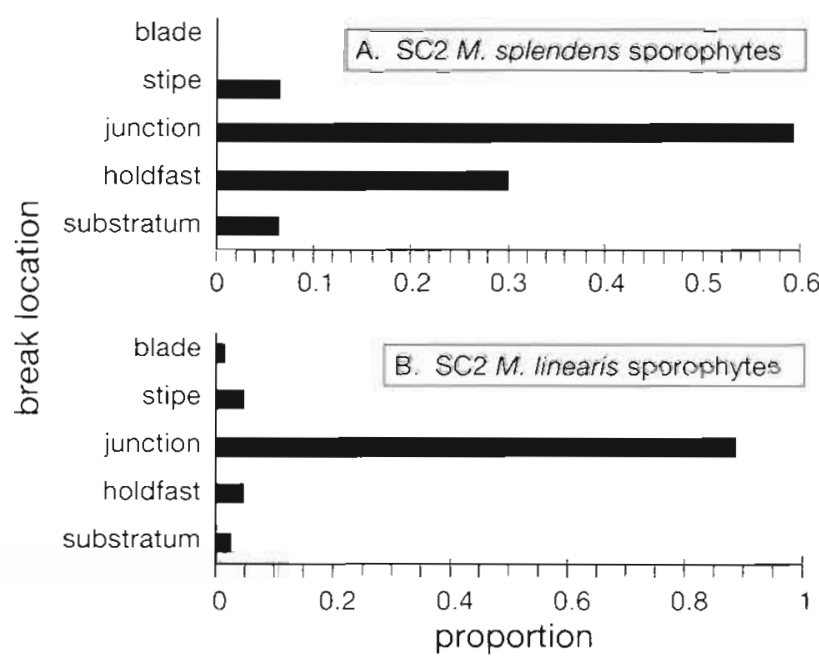

Fig. 5. Two examples (A and B) of Mazzaella spp. break location frequencies 


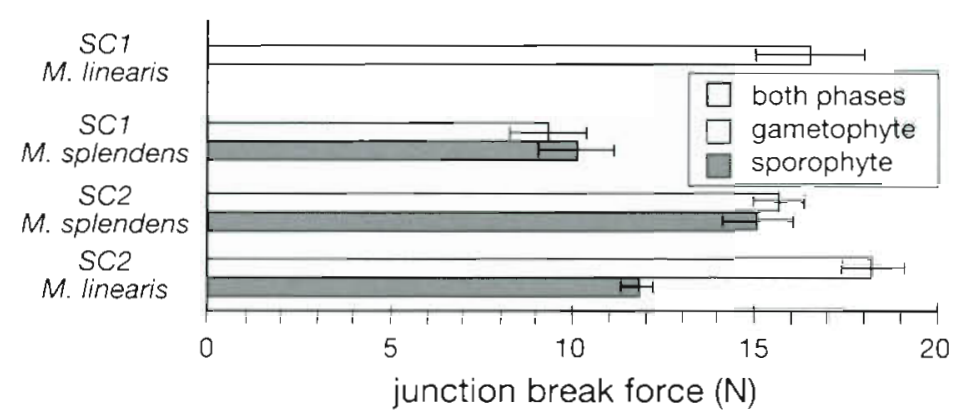

Fig. 6. Mean ( \pm 1 SEM) forces required to break the stipe/holdfast junction for both Mazzaella species and phases (see 'Results' for explanation of bias in SC1 $M$. linearis data) phytes, but phases did not significantly differ for $M$. splendens

Junction strength did not differ between phases of SC1 Mazzaella splendens ( $\mathrm{p}=$ 0.364 ), both of which had strengths similar to SC2 M. splendens (Fig. 7). For SC2, the complete ANOVA model had an $\mathrm{R}^{2}$ of $29 \%$ for strength variation and both effects were significant (Table 4). M. splendens had significantly greater junction strength than $M$. linearis and gametophytes of $M$. splendens were significantly stronger than sporophytes of $M$. splendensi phases of $M$. linearis were not significantly different.

Junction cross-sectional area did not differ between phases of SC1 Mazzaella splendens ( $\mathrm{p}=0.714$ ) and these area values were about $50 \%$ lower than values for SC2 $M$. splendens thalli (Fig. 8). SC2 M. linearis had a significantly greater junction area than $M$. splendens and the entire ANOVA model had an $\mathrm{R}^{2}$ of $28 \%$ for area variation (Table 5). Gametophyte cross-sectional area was significantly greater than sporophyte area for $M$. linearis but the 2 phases did not differ for M. splendens.

Based upon modeled hydrodynamic forces on SC1 Mazzaella splendens blades and measured forces required to break stipe/holdfast junctions, these short blades are predicted to have $50 \%$ survivorship at water velocities of approximately 22.0 to $25.0 \mathrm{~m} \mathrm{~s}^{-1}$ (Fig. 9A). Survivorship of SC2 blades of either species is predicted to be lower than for SC1 $M$. splendens. For SC2, $M$. linearis blades survive higher water velocities than $M$. splendens blades; $M$. linearis survive up to velocities of 8.0 to $11.0 \mathrm{~m} \mathrm{~s}^{-1}$ versus 3.0 to $5.0 \mathrm{~m} \mathrm{~s}^{-1}$ for M. splendens (Fig. 9B). Sporophytes are predicted to survive higher velocities than gametophytes for $M$. splendens but, for $M$. linearis, gametophyte survivorship is predicted to be greater.

\section{DISCUSSION}

The Nudibranch Point site is considered a high wave exposure site because there is little protection from open ocean swell and this is supported by the greater candy weight loss and the uplifted distribution of the kelp Hedophyllum sessile (Table 1). Although water velocities were not measured in this study, approximate ranges of water velocities at Nudibranch Point and Second Beach are indicated by comparing dominant taxa at these sites (Table 1) to other intertidal communities where velocities have been recorded. A conservative estimate of ca $14 \mathrm{~m} \mathrm{~s}^{-1}$ during non-
Fig. 7. Mean ( \pm 1 SEM) strength of the stipe/holdfast junction for both Mazzaella species and phases 
Table 4. Nested ANOVA table for differences among SC2 means of junction strength (square root transformed); significant differences: " $p<0.05, \cdots p<0.01$; F-test comparisons at the table bottom that share an underline were not significantly different $(p<0.05)$; splen. $=M$. splendens, lin. $=M$. linearis, gam. = gametophyte, sporo. $=$ sporophyte

\begin{tabular}{|lcrrr|}
\hline Effect & df & \multicolumn{1}{c}{ MS } & $F$ & p \\
\hline SPECIES & 1 & 11.181 & 47.898 &. \\
PHASE $\{$ S $\}$ & 2 & 0.718 & 3.075 & $\cdot$ \\
Error & 189 & 0.233 & & \\
splen. gam. & splen. sporo., & lin. gam. lin. sporo. & \\
\cline { 3 - 5 } & & &
\end{tabular}

Table 5. Nested ANOVA table for differences among $\mathrm{SC2}$ means of junction area (natural log transformed); significant differences: $\cdots p<0.01$; F-test comparisons at the table bottom that share an underline were not significantly different $(\mathrm{p}<$ $0.05)$ : splen $=M$. splendens, lin. $=M$. linearis, gam $=$ gameto phyte, sporo. $=$ sporophyte)

\begin{tabular}{|lcccc|}
\hline Effect & df & MS & $F$ & p \\
\hline SPECIES & 1 & 6.244 & 45.177 &.. \\
PHASE $\{$ S $\}$ & 2 & 1.550 & 11.216 &.$\cdot$ \\
Error & 189 & 0.138 & & \\
splen. gam. splen. sporo., & lin. gam. & lin. sporo. & \\
\hline
\end{tabular}

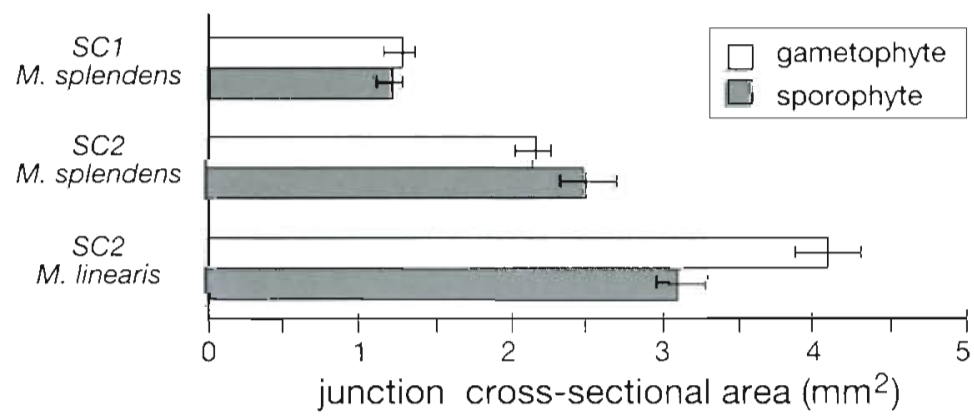

Fig. 8. Mean ( \pm 1 SEM) cross-sectional area of the stipe/hold-fast junction for both Mazzaella species and phases

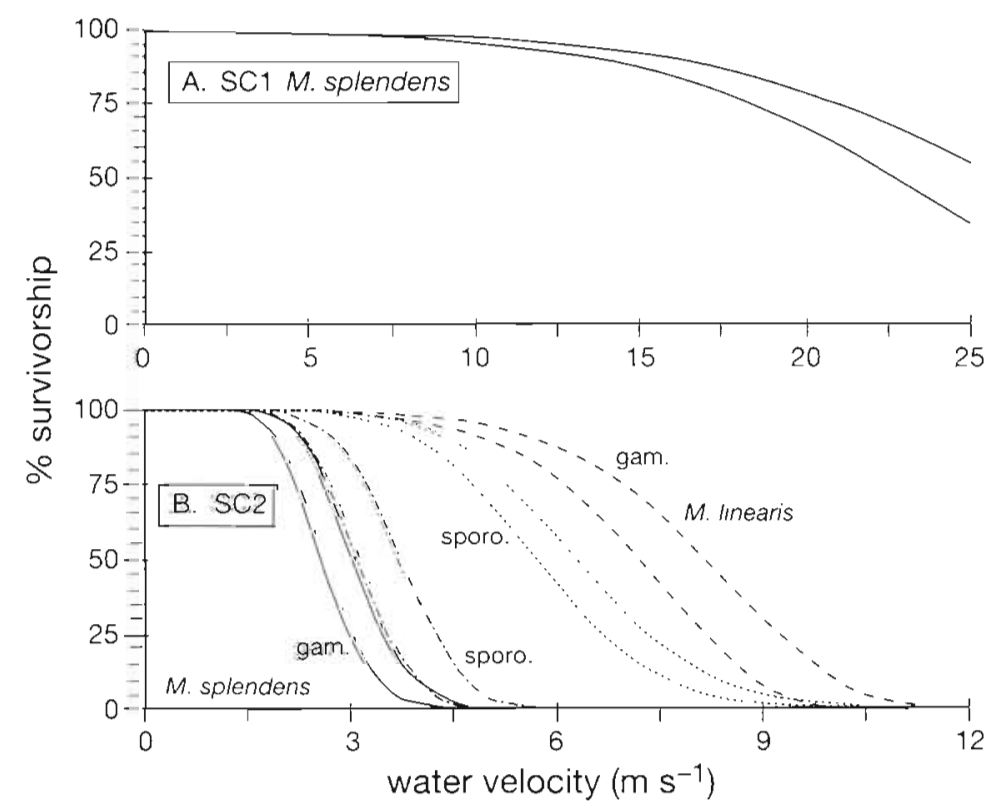

Fig. 9. Predicted blade survivorship for (A) both phases of SC1 Mazzaella splendens and (B) the 4 groups of SC2 blades (each pair of curves are upper and lower $95 \%$ confidence limits of planform area gam. = gametophyte, sporo. $=$ sporophyte) stormy conditions has been made for Tatoosh Island which receives full open ocean swell on the outer coast of Washington, USA (Denny et al. 1985). Tatoosh Island and Nudibranch Point share several organisms including the kelps Lessoniopsis littoralis, Laminaria setchellii, the barnacle Pollicipes polymerus and the mussel Mytilus californianus (Leigh et al. 1987). These invertebrates also occur on headlands of California, USA, where water velocities from 8.0 to $12.0 \mathrm{~m} \mathrm{~s}^{-1}$ have been recorded (Bell \& Denny 1994). At a waveprotected site in California, where the fucoid Pelvetia fastigiata was prevalent, velocities from 3.0 to $5.0 \mathrm{~m} \mathrm{~s}^{-1}$ were documented (Bell \& Denny 1994). In our study, predicted upper water velocity limits for blade survivorship of Mazzaella splendens (i.e. 3.0 to $5.0 \mathrm{~m} \mathrm{~s}^{-1}$ ) and $M$. linearis (i.e. 8.0 to $11.0 \mathrm{~m} \mathrm{~s}^{-1}$ ) are close to water velocity values cited above.

The absolute position of survivorship curves for SC2 Mazzaella splendens and SC2 $M$. linearis is in part dependent on the coefficient of drag $\left(C_{d}\right)$. The $C_{d}$ for a seaweed such as $M$. flaccida typically decreases as water velocity increases as flexible thalli reconfigure to a more streamlined configuration (Carrington 1990, Gaylord et al. 1994). Most of this reconfiguration occurs at water velocities below $2.0 \mathrm{~m} \mathrm{~s}^{-1}$ (Carrington 1990). Thus, for the purpose of modeling hydrodynamic forces at higher water velocities, we have assumed a constant $C_{\mathrm{d}}$ of 0.055 calculated from a velocity of $2.5 \mathrm{~m} \mathrm{~s}^{-1}$ (Carrington 1990). Gaylord et al. (1994) chose a different method of estimating $C_{d}$ by assuming that thalli continue to reconfigure exponentially at high water velocities. Consequently, the $C_{d}$ calculated 
by Gaylord et al. (1994) is much lower (0.01) than the value we have assumed. Using a lower $C_{d}$ would have the effect of shifting the absolute positions of our survivorship curves to higher water velocities (due to a reduction in the force contributed by drag), but would not affect relative positions of these curves. As a result, our conclusions about the relative survivorship of these 2 species remain unchanged

When the spring-scale was attached to the upper portion of a blade, the stipe/holdfast junction was always the most frequent break location as was the case for Mastocarpus papillatus (Carrington 1990, as 'stipe'). Thalli of many Rhodophyta, including those taxa in the Gigartinaceae, consist of a perennial holdfast (i.e. crust) that initiates annual upright blades or branched fronds. Since stress due to hydrodynamic forces should be concentrated on the small crosssectional area of the stipe. tissue failure at the junction ensures the holdtast survives to initiate new blades (Carrington 1990). Even when thalli of Mazzaella splendens and $M$. linearis broke in the holdfast, the majority of the holdfast remained attached to the substratum. Thus, hydrodynamic forces that blades should experience were modeled and compared to the force required to break the stipe/holdfast junction in order to predict the probability of blade survivorship.

SC1 blades of Mazzaella splendens are predicted to survive at high water velocities due to having a low planform area. Lower drag forces have also been noted for short individuals of Fucus vesiculosus and Chondrus crispus and the same reasons have been given (Norton 1991, Dudgeon \& Johnson 1992). Junction break forces for SC1 blades of both species were high relative to their thallus length. This early development of high junction break forces should increase the probability of withstanding increased hydrodynamic loads as blade planform area increases and spore production begins. However, as pointed out by Denny et al. (1985) and Carrington (1990), there will be an upper limit where planform area becomes so large that hydrodynamic forces result in junction failure. Blade morphology is the primary reason SC2 blades of $M$. splendens demonstrated lower survivorship than those of SC2 $M$. linearis at high water velocities. Due to the large planform area of its blade, SC2 blades of $M$. splendens will experience higher $F_{\mathrm{d}}$ and $F_{\mathrm{a}}$ values than blades of SC2 M. linearis. Junction break forces are not significantly different between $M$. splendens and $M$. linearis because $M$. splendens has strong tissue at the junction cross-section but the junction area is low whereas $M$. linearis has weaker tissue at the junction but more of it (Figs. 7 \& 8).

Phases of SC1 Mazzaella splendens should have about the same predicted blade survivorship because their planform areas and junction break forces are not signif- icantly different. Although SC2 phases of $M$. splendens had similar junction break forces, as blades of $M$. splendens grow longer, gametophytes become wider (Shaughnessy 1996) and have greater planform areas than SC2 sporophytes. Thus, long sporophyte blades are predicted to survive higher water velocities than long gametophyte blades. These predictions are consistent with studies in British Columbia describing the numerical dominance of $M$. splendens sporophytes when and where wave exposure is greatest (i.e. within the exposure range occupied by $M$. splendens) (Dyck et al. 1985, De Wreede \& Green 1990, Dyck \& De Wreede 1995). The shift in numerical dominance at the end of the summer, from gametophytes to sporophytes, may be due to fall storms culling the $M$. splendens population of gametophytes with greater planform areas. The late summer peak in gametophyte reproduction (De Wreede \& Green 1990) may decrease junction strength, thereby contributing to the susceptibility of this phase to fall storms. Hydrodynamic forces acting on blades are less likely to explain differences in phase abundance early in the growing season (De Wreede \& Green 1990, Dyck \& De Wreede 1995) when thalli are short and planform areas are still similar

In contrast, gametophyte blades of SC2 Mazzaella linearis should survive higher water velocities than sporophytes because gametophytes can withstand a significantly greater hydrodynamic force prior to junction break than sporophytes. Junction strength was similar between phases but junction break force for SC2 M. linearis gametophytes was greater because junction cross-sectional area of these gametophytes was significantly greater than that of sporophytes. These survivorship predictions are not consistent with data showing that sporophytes of $M$. linearis, like $M$. splendens, also dominate during the fall/winter in Barkley Sound (Shaughnessy unpubl. data). A better understanding of the effect of reproduction on tissue strength of each phase may explain the lack of agreement between predicted blade survivorship and actual blade abundance of each $M$. linearis phase.

Predictions from models need to be tested in the field. An experiment that monitored survivorship of both species in experimental common gardens (Shaughnessy 1994) supported predictions from the hydrodynamic model because short (i.e. $<5.0 \mathrm{~cm}$ ) blades did persist whereas most longer (i.e. 15.0 to $25.0 \mathrm{~cm}$ ) blades were removed within $24 \mathrm{~h}$. If the hydrodynamic model predicts that short blades of Mazzaella splendens should survive at the high wave exposure site of $M$. linearis, and some individuals of $M$. splendens can survive with short blades when transplanted into this site, what selective agent is preventing $M$. splendens from becoming established? Several alternative hypotheses need to be considered. Even 
though sites with each species are in close physical proximity in the low intertidal and water motion would seemingly ensure cross dispersal, the timing of spore release and distance of spore travel for each species need to be determined. Alternatively, spores of $M$. splendens may be reaching high exposure sites but may not be as successful attaching to the substratum at high water velocities relative to spores of $M$. linearis. Similarly, the majority of zygotes from Ascophyllum nodosum, a fucoid which occurs on low wave exposure shores, are removed by only 10 waves (Vadas et al. 1990). Vadas \& Bokn (data in Vadas et al. 1992) also reported that zygotes of Fucus evanescens, which occurs on shores subject to greater wave impact, were not as easily dislodged by water as zygotes of $A$. nodosum. If spores of $M$. splendens do attach at high exposure sites, the force required to remove a small holdfast (i.e. $<5.0 \mathrm{~mm}$ across) or blade (i.e. $<2.0 \mathrm{~cm}$ long) may be less than junction break forces documented in this study where blades from both size classes were removed from larger holdfasts (i.e. $>5.0 \mathrm{~mm}$ across). This is a possibility because blades of M. splendens are initiated by cells on the holdfast surface if the holdfast is $<1$ yr old but, if $>1$ yr old, initiation occurs within the holdfast (Norris \& Kim 1972, as Iridaea cordata). Selective herbivory or interspecific competition seem to be unlikely explanations. If there is a selective herbivore at high wave exposure sites in Barkley Sound, then it must be removing all blades of $M$. splendens before blades obtain recognizable sizes greater than ca $2.0 \mathrm{~cm}$ long. With regard to competition, $M$. linearis in Barkley Sound does not dominate space and there are no other obvious interspecific competitors against which $M$. splendens would lose and $M$. linearis win.

The hydrodynamic model predicts that blades of SC2 Mazzaella splendens should be absent from high wave exposure sites, which agrees with their absence at these sites in Barkley Sound. Blades of SC2 M. linearis should and do survive at high wave exposure sites not because they demonstrate greater junction break forces than SC2 M. splendens, but because planform area is so much lower for $M$. linearis. The model also predicts that SC1 blades of $M$. splendens will survive at high wave exposure sites despite the observation that no blades of $M$. splendens are visible to the unaided eye at these sites (Shaughnessy 1996). Thus, the absence of $M$. splendens from high wave exposure sites must be due to hydrodynamic forces, or some other type of selection, that is acting on a life history stage prior to the development of short blades (i.e. 2.5 to $6.0 \mathrm{~cm}$ length)

Acknowledgements. We thank Mark Denny for providing us with suggestions and the SYSTAT command file for fitting the modified Weibull model. We also appreciate the field and laboratory assistance of Brian Kerin and Christel Shaughnessy. The research was supported by the National Science and Engineering Research Council of Canada (no. 5-89872) to R.E.D.W.

Appendix 1. SYSTAT commands for fitting a modified Weibull model to a nonlinear cumulative probability distribution ('prob' and 'force' are variables in file.sys; $a=$ alpha, $b=$ beta $e=$ epsilon ]

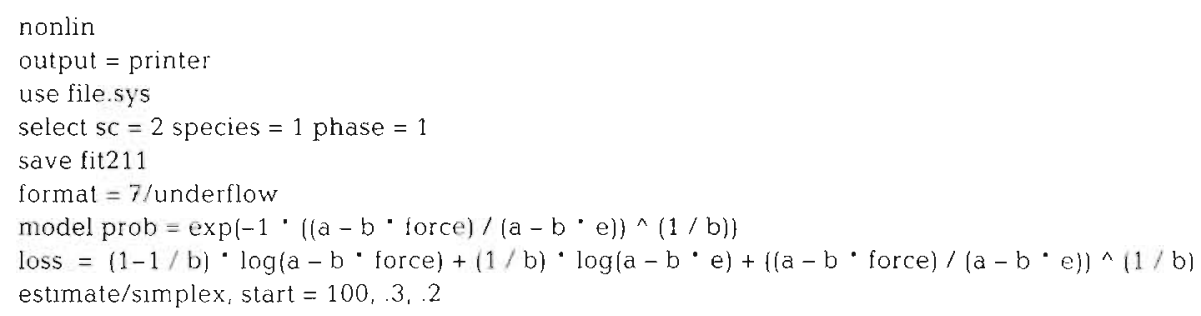

Appendix 2. Weibull equations used for calculating the probability of Mazzaella spp. junction failure for upper and lower $95 \%$ confidence limits of planform area $(A)$ for each SC, species and phase $F_{i}=$ drag + acceleration forces; gam.: gametophyte; sporo.: sporophyte

\begin{tabular}{|c|c|c|c|c|}
\hline $\mathrm{SC}$ & Species & Phase & $\begin{array}{c}A\left(m^{2}\right) \text { confidence } \\
\text { limits }\left(\times 10^{-4}\right)\end{array}$ & Equation \\
\hline 1 & M. splendens & Both & $3.93,5.04$ & $\left.\exp \mid-1\left(\left(5.7869222-0.1920233 F_{1}\right) /(5.7869222-0.1920233 \times 7.7743176)\right)^{1 / 01920273}\right\}$ \\
\hline 2 & M. splendens & gam. & $189.73,232.19$ & $\exp \left|-1\left(\left(5.2114793-0.1066609 F_{1}\right) /(5.2114793-0.1066609 \times 13.6788680)\right)^{1 / 1 / 1060609}\right|$ \\
\hline 2 & M. splendens & sporo. & $144.35,182.30$ & $\exp \left|-1\left(\left(6.7323058-0.2105819 F_{t}\right) /(6.7323058-0.2105819 \times 13.6701675)\right)^{1 / 02105819}\right|$ \\
\hline 2 & M. lineans & gam. & $55.33,67.76$ & $\left.\exp \mid-1\left(\left(11.6969484-0.3533598 F_{0}\right) /(11.6969484-0.3533598 \times 16.3458021)\right)^{1 / 03533598}\right]$ \\
\hline 2 & M. linearis & sporo. & $51.07,59.12$ & $\exp \left|-1\left(\left(4.3866753-0.0745484 F_{t}\right) /(4.3866753-0.0745484 \times 9.9671302)\right)^{1 / 00745484}\right|$ \\
\hline
\end{tabular}




\section{LITERATURE CITED}

Bell EC, Denny MW (1994) Quantifying 'wave exposure' a s.mple device for recording maximum velocity and results of its use at several field sites. J Exp Mar Biol Ecol 181:9-29

Carrington E (1990) Drag and dislodgment of an intertidal macroalga: consequences of morphological variation in Mastocarpus papillatus Kützing. J Exp Mar Biol Ecol 139: $185-200$

Cheshire AC, Hallam ND (1988) Morphology of the southern bull-kelp (Durvillaea potatorum, Durvilleales, Phaeophyta) from King Island (Bass Strait, Australia). Bot Mar 31:139-148

Denny MW (1987) Life in the maelstrom: the biomechanics of wave-swept rocky shores. TREE 2:61-66

Denny MW (1988) Biology and the mechanics of the waveswept environment. Princeton University Press, Princeton, NJ

Denny MW, Daniel TL, Koehl MAR (1985) Mechanical limits to size in wave-swept organisms. Ecol Monogr 55:69-102

Denny MW, Gaines SD (1990) On the prediction of maximal intertidal wave forces. Limnol Oceanogr 35:1-15

De Wreede RE, Green IG (1990) Patterns of gametophyte dominance of Iridaea splendens (Rhodophyta) in Vancouver Harbour, Vancouver, British Columbia, Canada. J Appl Phycol 2:27-34

Dudgeon SR, Johnson AS (1992) Thick vs thin: thallus morphology and tissue mechanics influence differential drag and dislodgment of two co-dominant seaweeds. J Exp Mar Biol Ecol 165:23-43

Dyck L, De Wreede RE (1995) Patterns of seasonal demographic change in alternate isomorphic stages of Mazzaella splendens (Gigartinales, Rhodophyta). Phycologia 34:390-395

Dyck L، De Wreede RE, Garbary D (1985) Life history phases in Iridaea cordata (Gigartinaceae): relative abundance and distribution from British Columbia to California. Jap J Phycol 33:225-232

Foster MS (1982) Factors controlling the intertidal zonation of Iridaea flaccida (Rhodophyta). J Phycol 18:285-294

Garbary DJ, De Wreede RE (1988) Life history phases in natural populations of Gigartinaceae (Rhodophyta): quantification using resorcinol. In: Lobban CS, Chapman DJ, Kremer BP (eds) Experimental phycology: a laboratory manual. Cambridge University Press, New York, p 174-178

Gardner MJ, Altman DG (1989) Statistics with confidenceconfidence intervals and statistical guidelines. British Medical Journal, London

This article was presented by C. Levings /Senior Editorial Advisor), Vancouver, British Columbia, Canada
Gaylord B. Blanchette CA, Denny MW (1994) Mechanical consequences of size in wave-swept algae. Ecol Monogr $64: 287-313$

Gutiérrez LM, Fernández C (1992) Water motion and morphology in Chondrus crispus. J Phycol 28:156-162

Hay ME, Norris JN (1984) Seasonal reproduction and aburdance of six sympatric species of Gracilaria Grev (Gracilariaceae; Rhodophyta) on a Caribbean subtidal sand plain. Hydrobiologia 116/117:63-94

Hommersand MH, Fredericq S, Freshwater DW (1994) Phylogenetic systematics and biogeography of the Gigartinaceae (Gigartinales, Rhodophyta) based on sequence analysis of rbcL. Bot Mar 37:193-203

Kim DH (1976) A study of the development of cystocarps and tetrasporangial sori in Gigartinaceae (Rhodophyta, Gigartinales). Nova Hedw 27:1-146

Leigh EG, Paine RT, Quinn JF, Suchanek TH (1987) Wave energy and intertidal productivity. Proc Natl Acad Sci USA 84:1314-1318

McCourt RM (1984a) Niche differences between sympatric Sargassum species in the northern Gulf of California. Mar Ecol Prog Ser 18:139-148

McCourt RM (1984b) Seasonal patterns of abundance, distributions, and phenology in relation to growth strategies of three Sargassum species. J Exp Mar Biol Ecol 74:141-156

Norris RE, Kim DH (1972) Development of thalli in some Gigartinaceae. In: Abbott IA, Kurogi $M$ (eds) Contributions to the systematics of benthic marine algae of the North Pacific. Jap J Phycol, Kobe, p 265-275

Norton TA (1991) Conflicting constraints on the form of intertidal algae. Br Phycol J 26:203-218

Shaughnessy FJ (1994) Population differentiation of two sympatric species of red algae, Mazzaella splendens and Mazzaella linearis, in Barkley Sound, British Columbia Canada. PhD thesis, University of British Columbia, Vancouver

Shaughnessy FJ (1996) Identification and microgeographic distribution of Mazzaella splendens and Mazzaella linearis (Gigartinaceae, Rhodophyta). Can J Bot (in press)

Vadas RL, Johnson S, Norton TA (1.992) Recruitment and mortality of early post-settlement stages of benthic algae. Br Phycol J 27:331-351

Vadas RL, Wright WA, Miller SL (1990) Recruatment of Ascophyllum nodosum: wave action as a source of mortality. Mar Ecol Prog Ser 61:263-272

Wilkinson L (1990) SYSTAT the system for statistics. SYSTAT, Inc, Evanston, IL

Manuscript first received: June 25, 1995

Revised version accepted: January 9, 1996 